\title{
Do movimento à mobilidade: uma análise semiótica da comunicação publicitária de marcas globais de automóveis ${ }^{1}$
}

\author{
Maria Alice de Faria Nogueira \\ Doutora; Universidade Federal do Rio de Janeiro, RJ, Brasil; \\ Universidade Estácio de Sá, Rio de Janeiro, RJ, Brasil \\ prof.maria.alice@gmail.com
}

\section{Resumo}

A propensão à mobilidade contemporânea altera radicalmente os modos de vida em todas as esferas de atuação cotidiana, constituindo uma Cultura da Mobilidade que envolve a tudo e a todos em novas possibilidades e experiências. O marketing e a publicidade têm um papel importante no estímulo à circulação global de pessoas, mercadorias e informação por serem parte integrante fundamental do movimento dos objetos. A partir de um panorama do contexto global de uma sociedade móvel, em rede e de riscos, este artigo tem como objetivo apresentar a maneira com que a propensão à mobilidade foi representada na publicidade, baseada na análise semiótica de anúncios de marcas globais de automóveis.

\section{Palavras-chave}

Cultura da mobilidade. Análise semiótica. Movimento.

Comunicação publicitária. Marcas automobilísticas.

\section{Introdução}

A vida em movimento não é uma prerrogativa da contemporaneidade. Desde o final do século XIX, uma sociedade baseada na intensa circulação de pessoas, objetos, informação e imagens vem sendo constituída, crescendo em intensidade e extensão. No entanto, foi a partir, principalmente, das décadas de 1970 e 1980, com o crescente desenvolvimento de complexos e interdependentes sistemas de mobilidades que colocam em circulação pessoas,

\footnotetext{
1 Versão preliminar desse artigo foi apresentada no TReC - 1ํ․ Simpósio Nacional sobre Transformações na Retórica do Consumo. GT Consumo, Tecnologia e Mobilidade. Faculdades Helio Alonso (FACHA). Rio de Janeiro. 19 de fevereiro, 2016.
} 
mercadorias, ideias e informação globalmente, que a mobilidade - isto é, o movimento positivamente valorado - torna-se parte importante da experiência cotidiana.

A propensão à mobilidade da vida contemporânea altera radicalmente os modos de vida em todas as esferas - social, cultural, política e econômica e, segundo Urry (2003), constitui uma Cultura da Mobilidade que envolve a tudo e a todos em novas possibilidades e experiências, assim como em novos constrangimentos, riscos e discursos.

0 marketing e a comunicação publicitária têm um papel importante no estímulo à circulação global de pessoas, mercadorias, ideias e informação por serem parte integrante fundamental do movimento dos objetos, assim como das mobilidades virtual dos meios e imaginativa dos signos de consumo (NOGUEIRA, 2015). Desta forma, a publicidade não escapa de ter o seu discurso adaptado a esta nova condição de mercado, no sentido de atender um público-alvo que também está constantemente em trânsito e que, cada dia mais, demanda por marcas, produtos e serviços que possam dar suporte a sua vida em movimento.

Neste artigo serão apresentados quatro anúncios impressos de marcas de automóveis veiculados no Brasil nos anos de 1982, 1998 e 2014. Analisados semioticamente (SANTAELLA, 2005), a série permitiu o mapeamento de, pelos menos, três maneiras diferentes com que a propensão à mobilidade foi representada no texto (verbal e não verbal) da publicidade, a saber: pelo objeto, pelo meio e pelo próprio discurso, ao longo das três décadas que separam a veiculação dos anúncios.

\section{A Cultura da mobilidade na sociedade contemporânea}

$\mathrm{Na}$ contemporaneidade, por escolha ou por obrigação, os indivíduos são constrangidos e experimentam a "vida em movimento" - mobile lives (ELLIOTT; URRY, 2010) - regida, em grande medida, pelos sistemas tecnológicos de transporte e de comunicação globais. Desenvolvidos com o intuito de proporcionar a circulação de pessoas, mercadorias e informação, os sistemas tecnológicos servem como infraestrutura para um robusto fluxo de mobilidades que, em um cenário globalizado, transcende o deslocamento físico e geográfico e assume novos contornos sociais, no interior dos quais a capacidade de mover-se virtual ou imaginativamente também é considerada. “[...] mobilidade espacial não é um conceito inequívoco e pode tanto referir-se ao movimento físico quanto ao movimento metafórico da comunicação, e concernem a pessoas, mercadorias, informação e ideias.", afirma Kaufmann (2002, p. 35). 
O crescimento dos fluxos de mobilidade possui como aspecto fundamental a velocidade. E em consequência da velocidade da técnica, a relação dos indivíduos com o tempo e com o espaço é alterada e torna-se também fluida e, em grande medida, não fixa. 0 incremento da velocidade e o consequente encurtamento das distâncias, em conjunto com a eficiência do deslocamento, como afirmam Kaufmann, Manfred e Joye (2004), causam forte impacto sobre as práticas culturais, econômicas e políticas nas sociedades modernas. As alterações nas dinâmicas sociais colocam a mobilidade como condição fundamental para a fruição do sujeito com seus grupos de referência e seus objetos de consumo.

Nesse sentido, a vida social contemporânea é mobilizada de diferentes formas que transcendem, conceitualmente, as formas com que as Ciências Sociais pensam a "mobilidade" - mobilidade residencial, migração, mobilidade diária e de viagem e turismo (KAUFMANN, 2002) - por envolverem novas espacialidades e temporalidades, as quais constituem, e são constituídas, pelo afeto da tecnologia no dia a dia dos indivíduos.

De acordo com Urry (2007), o momento cujas relações sociais da experiência cotidiana sofrem intervenções diretas de novos aparatos tecnológicos é também o momento no qual a mobilidade se impõe como "paradigma" para uma análise complexa das relações sociais e de poder. Segundo o autor, os crescentes fluxos de pessoas, mercadorias, ideias e informação criam uma dialética entre tecnologia e vida social, ou ainda, uma complexa interseção entre mobilidades e imobilidades, que abrem o caminho para novas condições de vida social na contemporaneidade.

Foi no sentido de pensar a vida social a partir do movimento que Urry (2007) e seus colaboradores propuseram um Paradigma das Novas Mobilidades, por meio do qual o mundo social é encarado a partir de uma série de ideologias, infraestruturas e práticas políticas, econômicas e sociais que envolvem, implicam ou cerceiam variados tipos de movimento de pessoas, ideias, informação e/ou objetos, “[...] especialmente no novo século no qual a mobilidade é um tema central." (URRY, 2007, p. 18).

0 autor aponta, ainda, para o fato de que as mais variadas entidades sociais pressupõem diferentes formas de movimento, real e/ou potencial. Neste sentido, pensar o mundo a partir das mobilidades proporciona ao pesquisador a possibilidade de articular as diversas formas de viagem, de transporte e de comunicação com as variadas maneiras como a vida social, econômica e política é organizada e vivenciada à distância e no interior de variadas condições espaço-temporais, as quais são vivenciadas individualmente e de diferentes formas. 
A noção de uma Cultura da Mobilidade (URRY, 2003) que a tudo e a todos envolve, em todas as esferas da vida cotidiana e que, em grande medida, regula nossas escolhas e afetos - familiares, profissionais, de lazer e de consumo -, guiou os estudos a propósito do discurso da comunicação publicitária de marcas globais, parte apresentada neste artigo². Em um mundo em que tudo gira e "A Lusitana roda" ${ }^{3}$, em que a vida acontece solta e sem direção, visto que em permanente estado de mobilidade (física, virtual ou imaginativa), a tendência é que indivíduos e grupos busquem por afiliações e parcerias pelas quais, apesar de seu caráter transitório e temporário, vão oferecer aos indivíduos a mobilidade em potência - ou motilidade (KAUFMANN, 2002) - necessária para escapar dos riscos da vida em movimento, assim como para vivenciar certa estabilidade no cenário social fluido contemporâneo (NOGUEIRA, 2015).

Uma das possibilidades de afiliação e parceria é com os objetos e/ou com as marcas que passam a oferecer aos seus potenciais clientes a motilidade como atributo concreto ou simbólico, mas fundamental para a vida na contemporaneidade. Neste sentido, em cada objeto, mesmo àqueles que não são diretamente relacionadas à capacidade de mover-se ou fazer mover, a publicidade eleva a mobilidade em potência como principal argumento discursivo de suas campanhas publicitárias, como já apresentado anteriormente em outros trabalhos (NOGUEIRA, 2009; 2011).

Para esse artigo, foram selecionados anúncios impressos de marcas globais de automóveis veiculados na revista Veja em junho de 1982, junho de 1998 e junho de 2014, que servem como uma pequena amostra de quanto, e como, a publicidade traduziu em seus discursos as mudanças sofridas no cenário contemporâneo, com especial ênfase no cenário brasileiro. A razão da comunicação publicitária de grandes marcas da indústria automobilística ter sido escolhida como o objeto de análise se justifica pelo automóvel já ser, naturalmente, um objeto constitutivo dos sistemas de mobilidade (URRY, 2007) e, teoricamente, já possuir um discurso contaminado pela cultura da mobilidade. No entanto, como veremos a seguir, o movimento físico e geográfico, isto é, o potencial de deslocamento e circulação do carro, foi sendo substituído pela oferta de mobilidade em potência, a partir de uma parceria entre a máquina e o indivíduo - os híbridos (URRY, 2007) - que altera a imagem do automóvel como um veículo e o eleva a categoria de meio, ou de um dispositivo móvel, como será apresentado a seguir.

\footnotetext{
2 Para saber mais sobre este assunto, ver Nogueira (2015).

3 “O mundo gira e A Lusitana roda”, slogan da Transportadora A Lusitana, de 1982. Disponível em: <http://www.lusitana.com.br>. Acesso em: 28 jun. 2015.
} 


\section{Análise semiótica das marcas globais de automóveis}

Para o objetivo desse artigo, a análise semiótica foi utilizada como uma ferramenta para a interpretação da comunicação publicitária por, segundo Santaella,

[...] nos levar a compreender qual é a natureza e quais são os poderes de referência dos signos, que informação transmitem e como eles se estruturam em sistemas, como funcionam, como são emitidos, produzidos e utilizados e que tipos de efeitos são capazes de provocar no receptor.. (SANTAELLA, 2005, p. 4).

Para tal tarefa, os anúncios foram encarados como processos comunicativos que, nos termos da autora, operam como signos e, por esta razão, possuem três faces a partir das quais podem ser analisados (SANTAELLA, 2005):

a) significação e representação (ou a análise das mensagens em si mesma): neste primeiro momento deve-se analisar o interior da mensagem por seus aspectos qualitativos, tais como, sua linguagem visual, por exemplo, as cores, linhas, formas, volumes, movimento, dinâmica etc. Em terminologia semiótica estaremos analisando os quali-signos das mensagens;

b) referência (ou a análise da referencialidade das mensagens): toda mensagem indica, refere-se ou se aplica a alguma coisa que está fora da própria mensagem. Sob esse aspecto, as mensagens também podem ser examinadas em três níveis: (1) quando a capacidade de referencialidade deriva do poder de sugestão de seus aspectos qualitativos, percebem-se seus ícones, (2) quando a referencialidade ao mundo real é direta e sem ambiguidades, é possível perceber seus índices, (3) quando as mensagens têm o poder de representar ideias abstratas, convencionais, estaremos falando de símbolos;

c) interpretação das mensagens: há três tipos de efeitos de interpretação que as mensagens podem provocar no receptor: os puramente emocionais; os reativos, quando a interpretação demanda uma ação; e os de caráter lógico, quando a mensagem leva o receptor a refletir. Esses aspectos foram considerados na análise dos anúncios e serviram como um roteiro que guiou a pesquisa.

Primeiro carro mundial lançado no Brasil, em 1982, o anúncio do Monza, da GM/Chevrolet (Figura 1) traz o título "Uma nova relação entre o homem e a máquina”(VEJA, 
1982, p. 68-69). Ao ter um layout muito diferente de outros anúncios que o leitor tem contato ao folhear a revista (normalmente ilustrados com fotos e/ou all type), a peça dirige a "retina mental", nos termos Santaella (2005), isto é, a atenção primária do leitor, para centro do anúncio: um desenho técnico como se saído da prancheta do designer da GM/Chevrolet, que mostra as medidas, vetores, posições e arranjos milimetricamente calculados para melhor ajustar o homem ao carro. Em um segundo momento, o caminho feito pelo olhar leva a atenção do receptor da mensagem para o texto que apresenta as novas características do Monza e seus aspectos tecnológicos singulares, resumidos na palavra "máquina" do título.

Depois deste contato inicial, o receptor, caso interessado, irá ler os features do produto com mais detalhamento, em cada sub-item do anúncio: freio/segurança; economia/motor; espaço/conforto, entre outros. Nesse sentido, é possível perceber a exaltação da tecnologia em todos os aspectos qualitativos do anúncio. Todo o discurso, verbal e não verbal da peça destaca e exalta a tecnologia envolvida no aperfeiçoamento da máquina para melhor atender o homem.

Como já foi dito, o potencial de movimento proporcionado por este tipo de produto é atributo inerente. Portanto, a mobilidade está presente no discurso não só a partir do próprio objeto, mas também da noção de híbrido, que se faz presente desde o título até a imagem no centro do anúncio. Além disso, é possível afirmar que a mensagem foi bem sucedida em provocar uma reação de caráter reativo no consumidor: o Monza foi eleito por revistas especializadas como o "Carro da Década", pelos seus resultados de desempenho técnico e de vendas.

Figura 1 - Anúncio em página dupla, Monza Chevrolet.

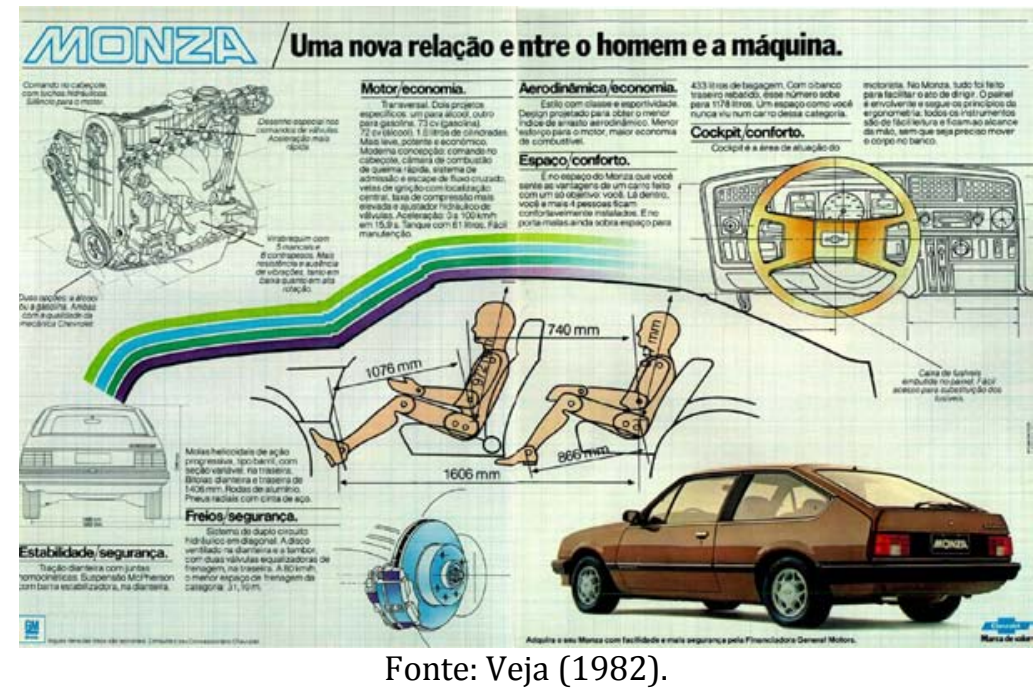


O próximo anúncio, da Ford para o Ford Escort (Figura 2), é de 1998. A cor (quase) dourada, em um fundo preto, chama a atenção do leitor da revista que retém o olhar. 0 fundo desfocado da paisagem na foto é um indício da velocidade do movimento do carro que, sendo uma station wagon, tem a parte de trás mais próxima do receptor da mensagem. 0 ângulo em que o Ford Escort aparece na foto tem a ver, também, com o principal feature anunciado do produto: o conforto. Afirma o título: "Sua casa pode ser mais confortável. Mas é imóvel" (VEJA, 1998, p. 28-29).

Nesse caso, a cultura da mobilidade fica bem evidente no discurso: tudo que se move ou que suporta sua [do consumidor] mobilidade é melhor. Sobre este aspecto, Sato e Perez (2013) afirmam que faz parte do processo de convencimento e de persuasão da publicidade apresentar a mobilidade sempre pelos seus aspectos considerados positivos, tais como a ampliação dos limites de espaço e de tempo, a possibilidade de ascensão, de evolução, de transcendência e de crescimento. Neste sentido, o carro (móvel) é melhor que a casa (imóvel) por possibilitar a circulação e o deslocamento "com conforto", tornando-se para o leitor e potencial comprador um símbolo da mobilidade contemporânea, ao mesmo tempo em que dá uma pista de que a vida (já na década de 1990) seria experimentada, em grande medida, em e no trânsito.

Figura 2 - Anúncio em página dupla, Ford Escort.

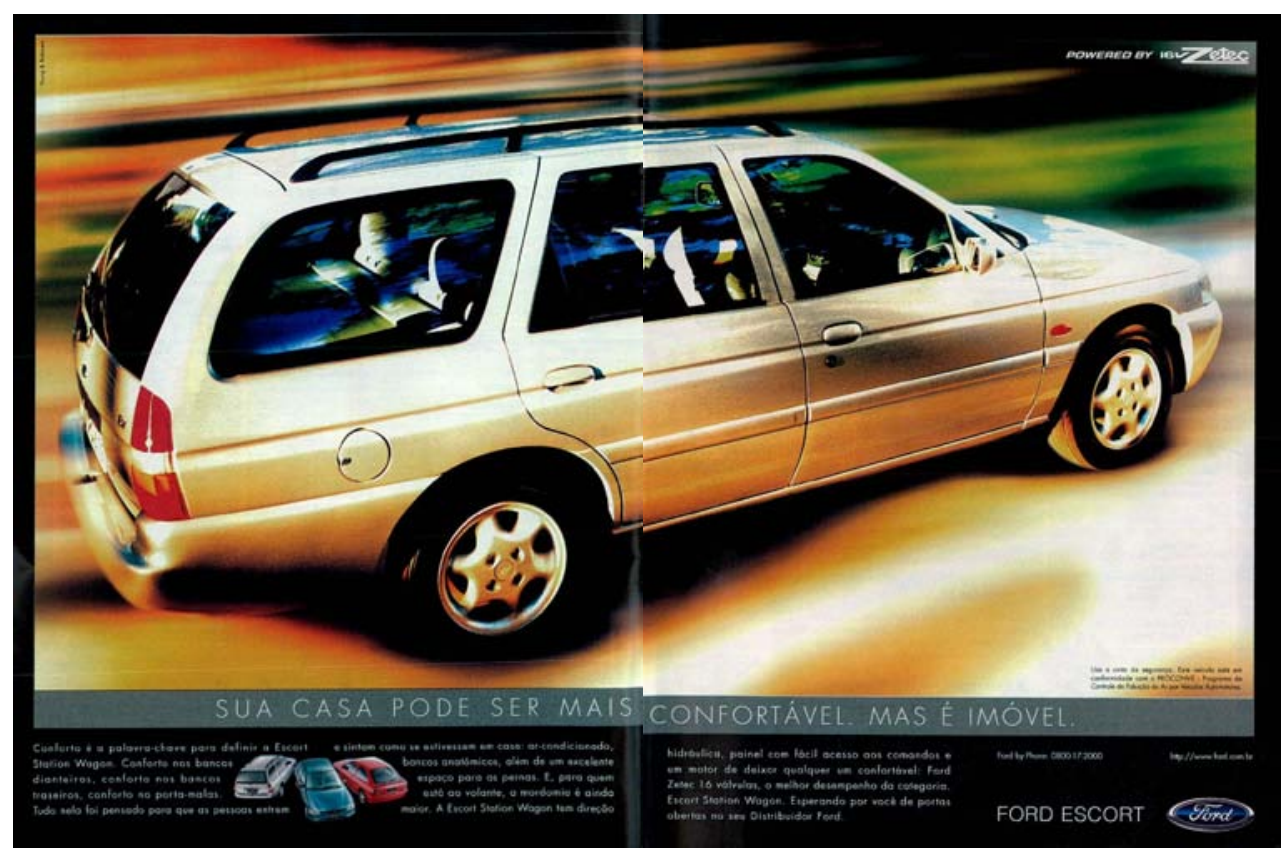

Fonte: Veja (1998). 
Os próximos anúncios selecionados são da Volkswagen (VW, Figuras 3 e 4), veiculados em 2014, com uma semana de diferença, na época da Copa do Mundo FIFA, no Brasil. A despeito dos 32 anos que separam os períodos analisados, de 1982 para 2014, pouca coisa mudou nos layouts de anúncios de automóveis. Como produtos, grande parte deles continua sendo exposto em um mesmo desenho gráfico: o carro no meio do layout, inserido em uma "moldura" que ocupa $90 \%$ do espaço, com os $10 \%$ restantes situados abaixo da imagem, reservados para o texto."

No caso dos anúncios da $V W$, os carros são apresentados estacionados e não em movimento, como no anúncio anterior. A razão desta abordagem discursiva é feita com base nas mudanças contextuais experimentadas pelos consumidores ao longo das últimas décadas: mais forte ainda do que em 1998, a cultura da mobilidade já faz tanto parte do cotidiano que o movimento, leia-se aqui, o deslocamento físico e geográfico das pessoas e dos objetos, é suplantado, tecnologicamente, pelas possibilidades de mobilidade virtual e imaginativa, não só das ideias e de informação, como também dos indivíduos consumidores e das mercadorias.

Figura 3 - Anúncio em página dupla, Linha Gol e Voyage, Volkswagen.

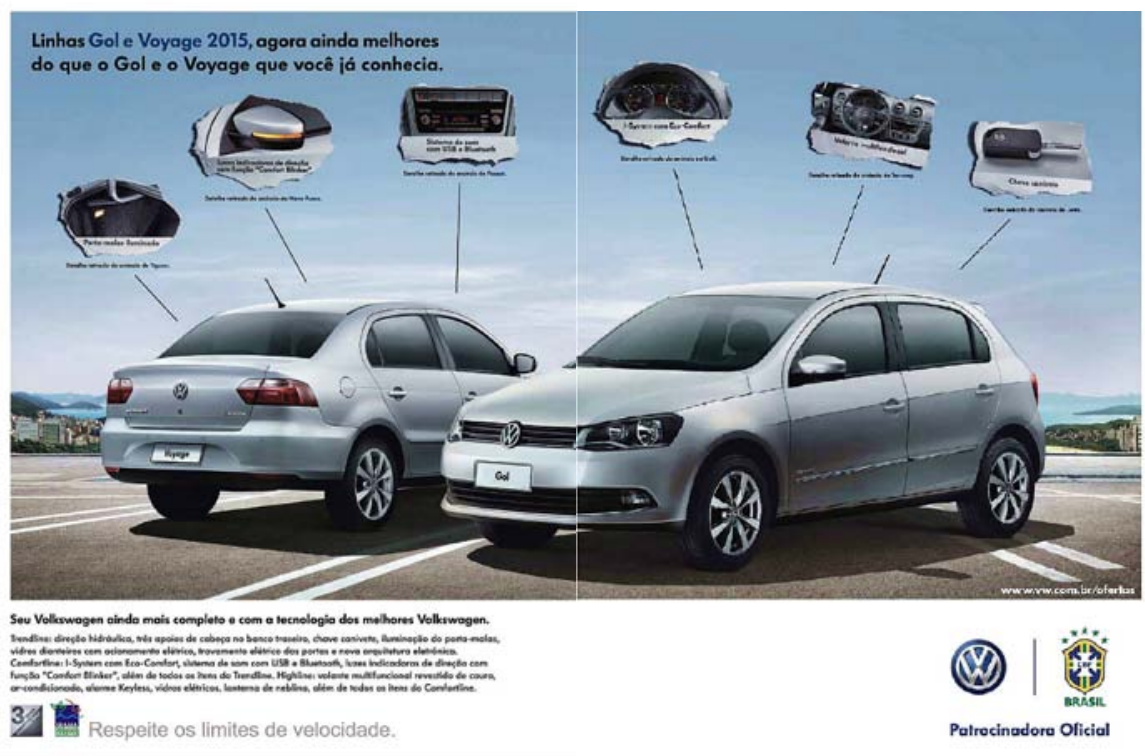

Fonte:Veja (2014a).

Especialmente, no segundo anúncio (Figura 4), chama a atenção o fato de o próprio produto ser apresentado como uma foto em um tablet e de todos os argumentos de vendas serem visualmente relacionados em telas de smartphones e reforçados pelo título: "Perfeito 
para quem gosta de ser sofisticado e tecnológico ao mesmo tempo" (VEJA, 2014b, p. 10-11). Para completar esse posicionamento pela tecnologia, em última instância, pela cultura da mobilidade, no anúncio do Voyage Evidence há um QR Code, além do endereço do site da VW para qualquer outra informação. Aqui, a mobilidade física ou geográfica e a mobilidade virtual ou imaginativa se misturam, isto é, hibridizam, empoderando o indivíduo com essa integração entre tecnologias e mobilidades. Nesse sentido, o movimento do carro é substituído pela mobilidade virtual e imaginativa proposta não só pela tecnologia que o carro possui, mas pela maneira discursiva em que os atributos do carro são apresentados e que tornam o Voyage "um sedan fora do comum" (VEJA, 2014b, p. 10-11), como sugere o slogan do anúncio.

Figura 4 - Anúncio em página dupla, Voyage, Volkswagen.

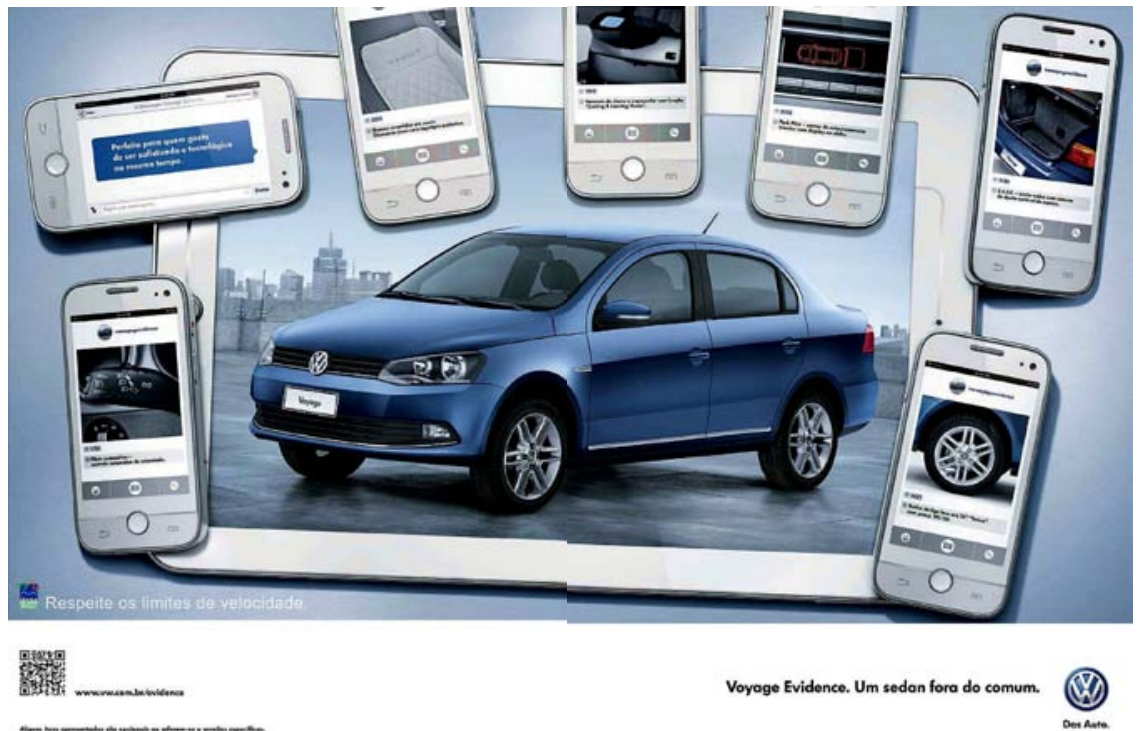

Fonte: Veja (2014b).

\section{Do movimento à mobilidade: considerações finais}

O fazer publicitário mudou muito entre 1982 e 2014, como foi possível verificar nessa investigação. Uma das características mais visualmente perceptíveis desta mudança na propaganda em mídia impressa, como na Revista Veja, fonte na qual os anúncios foram selecionados, foi o peso do texto no layout. Como é possível perceber na peça do Monza, grande parte do layout do anúncio é dedicada ao texto e não à imagem. No caso específico da peça em questão, ainda havia uma série de novidades técnicas e tecnológicas que precisavam ser explicadas aos consumidores. Uma propaganda mais informativa, nesse 
caso, fazia todo o sentido. No entanto, se pensarmos na construção visual da peça, o modelo segue o mesmo: a parte mais importante do anúncio - o carro ou o desenho dele - no centro da peça e as informações técnicas diagramadas ao redor, levando o olhar do leitor a percorrer todo o texto. A única diferença é que na peça de 2014 o texto é visual, com a informação sendo transmitida por meio de fotos nas telas dos celulares.

Em 1998, o discurso da cultura da mobilidade aparece mais nos anúncios, tanto nas imagens dos carros em movimento quanto nos textos, com a tecnologia a serviço da velocidade. 0 mundo fluido e da circulação, característico da sociedade contemporânea globalizada, foi mostrado como um pano de fundo da argumentação e a velocidade proporcionada pela técnica, característica deste mundo móvel e tecnológico, foi usada como argumento de vendas, mas relacionada ao conforto e à segurança. Na virada para os anos 2000, o anúncio da Ford Escort já ressaltava, no título, o valor da mobilidade enquanto capital e afirmava ser o carro mais precioso que uma casa, exatamente por ser móvel e, portanto, possuir mobilidade em potência.

Diferentemente de 1998, em 2014 a motilidade que os carros oferecem para o (a) usuário (a) ultrapassa a barreira do físico e torna-se, também, virtual. Entre tantas tecnologias presentes nos automóveis, o acesso à internet pelo bluetooth é uma delas, como é oferecido pelo Voyage da $V W$. Com a mobilidade urbana e o trânsito cada vez piores nas grandes cidades, especialmente nas grandes cidades brasileiras onde, normalmente, não há uma rede ônibus/metrô/trem que facilite a circulação dos moradores/trabalhadores da cidade, a cultura da mobilidade se impõe e a organização da vida à distância, inclusive durante o deslocamento, se faz necessária.

Como vimos, a vida móvelpressupõe novos arranjos e combinações espaçotemporais do indivíduo e, por esta razão, demanda objetos que o auxiliem na organização da vida à distância que, em grande parte, é operada em modos de presença e de ausência que são (re)configurados enquanto em movimento. Um dos objetos que melhor representa esta nova condição de vida é o aparelho celular que traz em seu chip todas as informações pessoais e personalizadas do indivíduo (URRY, 2007). Ao possibilitar o acesso facilitado à internet, à agenda, aos contatos, enfim, ao mundo virtual, por meio do celular do (a) motorista, o automóvel torna-se parte da vida handy do indivíduo. Neste sentido, assim como qualquer outro dispositivo móvel, cada dia mais o carro "[...] é a extensão do homem [...]" (MCLUHAN, 1974) e, enquanto objeto, tem ganhado novas potencialidades ao longo das últimas três décadas, alterando, inclusive, seu valor como commodity. Nesse sentido, mais do 
que nunca, "[...] o telefone celular e os carros são os gêmeos da modernidade tardia." (URRY, 2007, p. 174) e, atualmente, operam em novas parcerias que os tornam como "máquinas habitadas" ou inhabited machines, nos termos de Urry (2007, p. 179), que são pensadas como artefatos "entrelaçados" ao corpo ou que servem como uma extensão do corpo, como já acima citado.

Dessa forma, ao longo do período analisado pela investigação, a publicidade encampou em seu discurso as novas potencialidades de movimento relacionadas ao carro e, com isso, passou a destacar em seus argumentos de vendas a tecnologia de informação/comunicação, portanto, a mobilidade virtual e imaginativa. A despeito do desempenho técnico, da mecânica e/ou da economia em combustível, por exemplo, o discurso joga luz nas novas características do produto e aponta para um deslocamento discursivo do movimento para a mobilidade, como afirma o título desse artigo.

Complementando o estudo, em março de 2016, a Volkswagen lançou a campanha dos novos modelos Gol e Voyage 2017, que tem como slogan a hashtag \#ocarroconectado. Todo o discurso é pela conexão, não só fisicamente, de um ponto a outro, mas de pessoas, pela possibilidade do contato virtual que o carro oferece enquanto meio, ou, em certa medida, como um "dispositivo móvel", mais no sentido da mobilidade do que do movimento. Esse caminho discursivo acompanha as novas tendências da indústria automobilística que busca novos formatos para "o carro do futuro", incluindo, por exemplo, o carro autônomo, que, através da tecnologia, controla a si mesmo enquanto o condutor, conectado, pode trabalhar ou se divertir - via internet - durante o percurso. Algumas questões a propósito do carro autônomo têm sido discutidas tanto na indústria quanto em pesquisas acadêmicas sobre a segurança dos passageiros e sobre os complexos sistemas de comunicação e transporte que se juntam, ainda mais, nesse projeto. Contudo, a despeito de todas as questões suscitadas pela novidade, o mais interessante nisso tudo é que a Google é uma das empresas que está à frente das pesquisas sobre o carro autônomo, e não a $V W$, para citar uma das montadoras globais da atualidade. Essa migração da indústria automobilística das tradicionais montadoras para uma empresa cujo core business é a tecnologia aponta para um cenário futuro em que o título do anúncio do Ford Escort, de 1998, aqui analisado, não poderia ser mais atual. 


\section{Referências}

ELLIOTT, Anthony; URRY, John. Mobile Lives: self, excess and nature. Abingdon: Routlegde, 2010.

KAUFMANN, Vincent. Re-thinking Mobility. Londres: Ashgate, 2002.

KAUFMANN, Vincent; MANFRED, Max Bergman; JOYE, Dominique. Motility: mobility as capital. International Journal of Urban and Regional Research, Malden, v. 28, n. 4, p. 745756, 2004.

MCLUHAN, Marshall. Os meios de comunicação como extensão do homem. São Paulo: Cultrix, 1974.

NOGUEIRA, Maria Alice de Faria. As representações da cultura da mobilidade na comunicação publicitária das marcas globais. In: CONFEDERACIÓN IBEROAMERICANA DE ASOCIACIONES CIENTÍFICAS Y ACADÉMICAS DE LA COMUNICACIÓN, 1., 2011, São Paulo. Anais... São Paulo: USP, 2011.

NOGUEIRA, Maria Alice de Faria. Globalização, consumo e mobilidade: mais pessoas vão com Visa. In: CONGRESSO DE ESTUDANTES DE PÓS GRADUAÇÃO EM COMUNICAÇÃO, 4., 2009, Niterói. Anais... Niterói: UFF, 2009.

NOGUEIRA, Maria Alice de Faria. Mobilidade em potência e discurso publicitário na sociedade contemporânea globalizada: Brasil, 1982-2014. 2015. Tese (Doutorado) Programa de Pós-Graduação em História, Política e Bens Culturais, Centro de Pesquisa e Documentação de História Contemporânea do Brasil, Fundação Getúlio Vargas, Rio de Janeiro, 2015. Disponível em: <http://hdl.handle.net/10438/13704>. Acesso em: 22 mar. 2017.

SANTAELLA, Lucia. Semiótica aplicada. São Paulo: Thompson, 2005.

SATO, Silvio Koiti; PEREZ, Clotilde. Mobilidade e a sobreposição de sentidos nas representações publicitárias. In: ENCONTRO DOS GRUPOS DE PESQUISA EM COMUNICAÇÃO, 13., 2013, Manaus. Anais... Manaus: UFAM, 2013.

URRY, John. Mobile Cultures. Lancaster: Department of Sociology of Lancaster University, 2003. Disponível em: <http://www.lancaster.ac.uk/fass/resources/sociology-onlinepapers/papers/urry-mobile-cultures.pdf>. Acesso em: 23 mar. 2017.

URRY, John. Mobilities. Cambridge: Polity Press, 2007.

VEJA, n. 719, p. 68-69, 16 jun. 1982. Disponível em: <http://veja.abril.com.br/acervodigital/>. Acesso em: 9 set. 2014

VEJA, n. 1550, p. 28-29, 10 jun. 1998. Disponível em: <http://veja.abril.com.br/acervodigital/>. Acesso em: 18 jun. 2013 
VEJA, n. 2377, p. 18-19, 11 jun. 2014a. Disponível em:

<http://veja.abril.com.br/acervodigital/>. Acesso em: 20 dez. 2014.

VEJA, n. 2378, p. 10-11, 18 jun. 2014b. Disponível em:

<http://veja.abril.com.br/acervodigital/>. Acesso em: 20 dez. 2014.

\title{
From movement to mobility: a semiotic analysis of automobiles global brands
}

\begin{abstract}
The propensity to mobility changes radically ways of life in all spheres of everyday activities, constituting a Mobile Culture that involves everything and everyone in new possibilities and experiences. Marketing and advertising play an important role in stimulating global circulation of people, goods and information for being a key member of the movement of objects. From an overview of the global context of a mobile risks society, this article aims to present the way the propensity to mobility was represented in advertising, based on a semiotic analysis of automobile global brands advertisements.
\end{abstract}

\section{Keywords}

Mobility culture. Semiotic analysis. Movement. Global advertising. Automobile brands.

Recebido em 17/11/2016

Aceito em 12/01/2017 